\title{
WEB-BASED DELIVERY SYSTEM FOR DISASTER PREVENTION INFORMATION USING A NEW JMA DPI XML FORMAT AND AMEDAS DATA
}

\author{
Masahiro Nishio ${ }^{\text {a, } * \text {, Masatoshi Mori }}{ }^{\text {a }}$ \\ ${ }^{a}$ Kinki University School of Humanity-Oriented Science and Engineering, Kayanomori, Iizuka city, JP \\ Commission IV, WG IV/1
}

KEY WORDS: JMA XML format, GIS, web-based, Google Maps, Open Source Software, Disaster prevention

\begin{abstract}
:
The Automated Meteorological Data Acquisition System (AMeDAS) Data is used along with compound disaster information for a geographic information system (GIS) by integration into the Japan Meteorological Agency (JMA) disaster prevention information XML data. A JMA XML format is a next generation format that contains weather warnings, tsunami warnings, and earthquake information, etc. However, it is not possible to process it by reading disaster prevention information XML Data and AMeDAS Data directly to the GIS system. Therefore, development of a program that converts the data structure is important to consolidate a variety of disaster prevention information on the GIS system. Information on escape routes and evacuation sites, etc. were given as points for regional meteorological observation forecasts using AMeDAS Data by disaster prevention information XML data and integrating it where the disaster was generated, giving a range of expansion of damage and a damage level. There are two main aims; the first is to deliver these compound data of disaster prevention information XML data and AMeDAS Data via the Internet. The second aim is to provide GIS files (shapefile format) of these data to such as local governments for their individual analysis. This was furthermore confirmed to enable the construction of a system using WebGIS (Google Maps) and Open Source Software GIS to monitor disaster information at low cost.
\end{abstract}

\section{INTRODUCTION}

The Japan Meteorological Agency (JMA) has decided to deliver all Disaster Prevention Information (DPI) data in a new JMA format to users, mainly local governments. This data is in an XML format. The DPI data contains weather warnings, tsunami warnings, and earthquake information, etc. Previous DPI data was delivered by fax and low-speed communication lines, such as in JMA telegram forms, which differ in format respectively, and are not effective. The XML format is a general format for data delivery, transformation and storage, so it is expected to enable monitoring of DPI data and analysis by GIS software. The present DPI XML format is more detailed to suit our highly information-oriented modern society, and is more effectively advanced. There are some cases of JMA meteorological observational data (rainfall etc.) using real-time display systems (Ushiyama et al., 2002) on the Internet. However, there is no system that can share information by consolidating a new JMA DPI XML format (offer in May, 2011) and the weather information (regional the observation data), etc. in geographic information system (GIS) in real time. We have developed a new system to utilize this JMA DPI XML format using a webbased interface and GIS framework. This system can be used for real-time protection of the municipality, enabling the disaster prevention information, to accumulate JMA DPI, and to use past disaster prevention information. There is another type of DPI data in the Meteorological Agency. This data is from the Automated Meteorological Data Acquisition System (AMeDAS). Using the rainfall and the precipitation data, etc is an effective technique in analyzing naturally caused damage (flood and sediment disaster etc. of rivers) (See Beyene et al., 20 al., 2008; Domenikiotis et al., 2010; Chang et al., 2011; Suk et al., 2009). This is effective data for the analysis of the wealth of weather information etc. in Japan from AMeDAS for research in rainfall, precipitation and the like (e.g., SOLA. Kanada et al., 2008; SOLA. Iwasaki et al., 2009). The AMeDAS data is used to analyze and to analyze the rainfall disaster (JNDS. Ushiyama 2003). Unfortunately, AMeDAS data is not contained in the new DPI XML data. So we have integrated AMeDAS data with the new DPI XML data for much higher efficiency. The integration of disaster prevention information in the GIS system is a promising method for protecting the municipality. The purpose of this research is expected to become an effective tool for protecting the municipality in real time collecting, integration of information from AMeDAS data (rainfall etc.) that supplements the content of disaster prevention information in addition to disaster prevention information announced by the Meteorological Agency. Moreover, this system was confirmed as a promising method for monitoring disaster prevention information with cheap system construction using WebGIS (Google Maps) and Open Source Software GIS.

\section{NEW JMA DPI XML DATA}

The offer of new JMA DPI XML data was begun from JMA in May, 2011. The new JMA DPI XML data (August, year of JMA XML Ver1.1 2010) is highly general in the provided idiosyncratic form of each type of information. Even if information such as the weather, earthquakes, and typhoons is different, the user has a structure that can be consciously processed. The entire structure of JMA DPI XML data is composed of Management Division (control), rivet-and-bolt

\footnotetext{
* Corresponding author.

E-mail address: nishio@cc.kurume-it.ac.jp (M. Nishio), mori@fuk.kindai.ac.jp (M. Mori).
} 
header part (head), and content part (body). The Management Division (control) is a part composed by the item that gives control information in the cable. The rivet-and-bolt header part (head) is a part where the information type (weather information and earthquake information, etc.) and the outline sentence (find) are mainly composed of the form attempted to be shared at the available hour (time). The user understands the time announced from processing the rivet-and-bolt header part regardless of the type of information such as weather or earthquakes. JMA DPI XML data might be composed only of the Management Division and the rivet-and-bolt header part depending on the type of emergency and the associated information. The JMA DPI XML mechanism is such that the data is delivered from JMA to the prefectural office by District Meteorological Observatories in each administrative division. The sample data used in the present study is a general warning, a weather warning, typhoon information, earthquake information, and real-time earthquake information, and also includes an eruption warning and a forecast, etc. Figure 1 shows new JMA DPI XML data concerning hypocenter and seismic intensity information. The JMA DPI XML data is encoded using UTF-8. JIS X 0201 characters except Katakana, and the JIS X 0208 range is used for the character set. Neither single byte, NEC special characters nor IBM ESC are used. The W3C XML Schema is adopted for the XML schema. AMeDAS data is converted according to the data structure of this new JMA DPI XML.

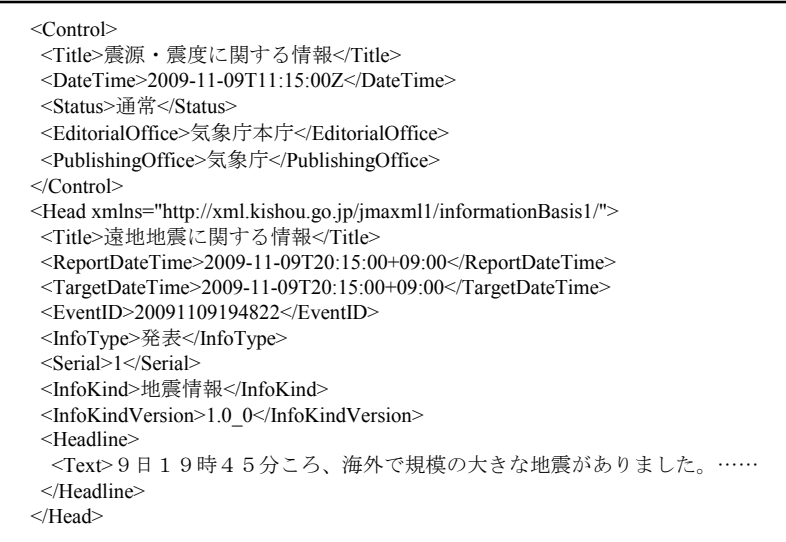

Figure 1. JMA DPI XML data format

\section{USE OF JMA DPI XML DATA WITH WEBGIS}

This system can process the JMA DPI XML data in real time. It is not easy to display disaster information (typhoon and earthquake information, etc.) directly in a Web browser even though the DPI XML format is a general XML form. This system can be operated without trouble on a general Web browser and if Java and JavaScript are installed and enabled in the computer. First of all, we developed the web-based system using the Google Maps API with Google Maps. The imaging process was accomplished by using Web GIS (Google Maps) as a technique for visually expressing the image through DPI based on the DPI XML data (information, typhoon information report, and volcanic information, etc concerning the hypocenter and seismic intensity), position information (latitude-longitude information), and disaster information. The Google Maps service can build the DPI XML data on Google Maps through using an open-to-the-public API besides use with the unit in the web-page. The function and Ajax (Asynchronous JavaScript +
XML) of Google Maps API were used with JavaScript for these imaging processes. Figure 2 shows the flow of data processing to display disaster information on Google Maps. Figure 3 shows a scene of JMA DPI XML data typhoon course information on a webpage by using the Google Maps API. Figure 4 shows a scene of different earthquake information data of a JMA DPI XML variety. After downloading the JMA DPI XML data using the Ajax framework, the system of this Web-base can process the data in real time. This system is a cheap and efficient method for high-speed monitoring hazard information.

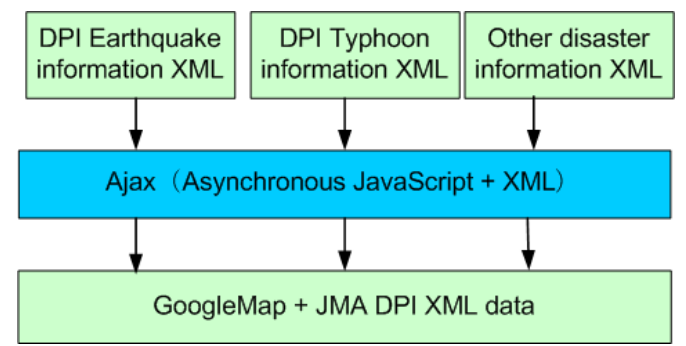

Figure 2. Data processing in Google Maps

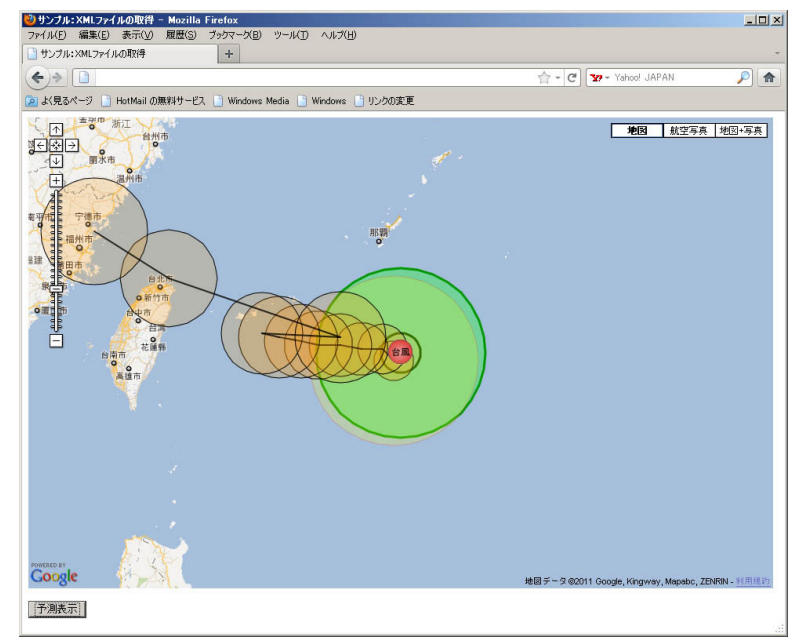

Figure 3. Typhoon scene on Google Maps

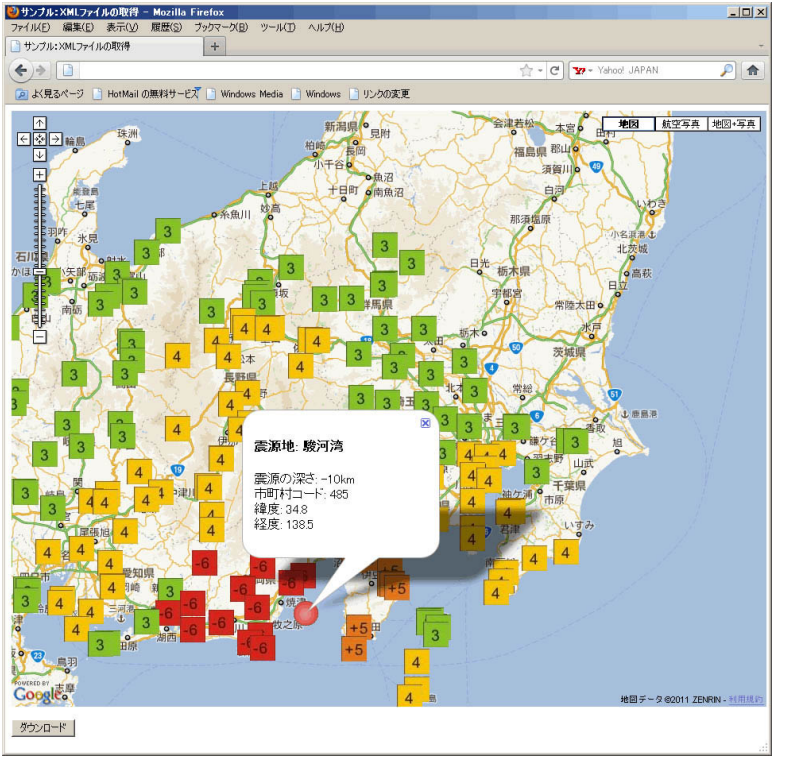

Figure 4. Earthquake scene on Google Maps 


\section{USE OF JMA DPI XML DATA WITH GIS SOFTWARE}

Data is converted into a file format (shapefile format) that can use the DPI XML format with a general GIS, using it with the GIS software. JAXP (Java API for XML Processing) of the Java API (Application Program Interface) was used to analyze the DPI XML data format. The JAXP has the validation for the XML document and the interface for parsing. We extract the data (disaster information) used with the GIS software from the JMA DPI XML data by using this Java API. After the DPI $\mathrm{XML}$ data is received, the DPI XML form is converted to a shapefile format in real-time and is processed with the tool (program) developed in Java and Perl languages. This converted DPI XML data (shapefile) can be used with open source software GIS (Quantum GIS, GrassGIS). Figure 5 shows the flow that extracts and processes the disaster information data (earthquake information etc.) from DPI XML using the Java API.

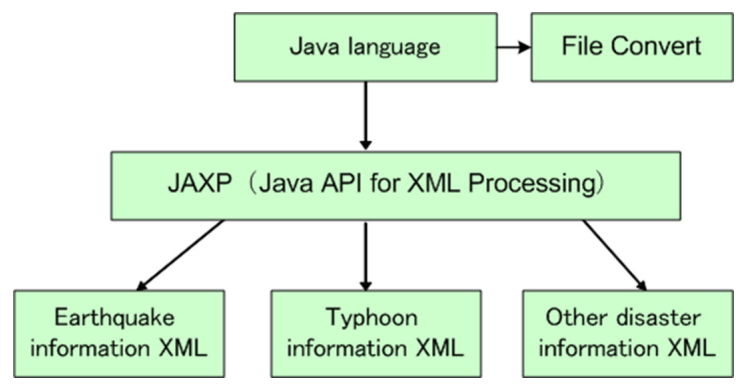

Figure 5. DPI XML data conversion

The imaging was processed using satellite imaging, an aerial photograph, and basic map information (numeric basic map information) as a technique for treating disaster information in more detail with an Open Source Software GIS. This has the frame of the digital map through information (reference point, coastline, road edge, and shore line measurements) that shows the position though basic map information that forms a standard by which to decide the position on the digital map. Figure 6 shows a scene of earthquake information converted from the DPI XML format into a shapefile in the GIS. Also, other disaster information such as a local hazard map could be integrated with the DPI shapefile on the GIS system for individual client use. Several basic DPI XML formats such as typhoon information, weather warnings, tidal wave warnings and earthquake information are already available for web-based monitor systems and GIS systems. The DPI XML data is received in real-time from JMA, and this system that we have developed can disclose and share information within 15 minutes at latest.

\section{INTEGRATION OF AMEDAS DATA AND JMA DPI XML DATA}

The JMA has the DPI data of the Automated Meteorological Data Acquisition System (AMeDAS) in addition to the DPI XML data. AMeDAS is a high-resolution surface observation network, and contains precipitation, air temperature, wind direction and speed, and sunshine duration observations from 1,300 stations located at an average interval of $17 \mathrm{~km}$ throughout Japan. They make observations every 10 minutes. Unfortunately, AMeDAS data is not contained in the new DPI XML data, so we have integrated AMeDAS data with the new
DPI XML data for much higher efficiency. The original AMeDAS data is formatted in binary code, which is in a special and uncommon format.

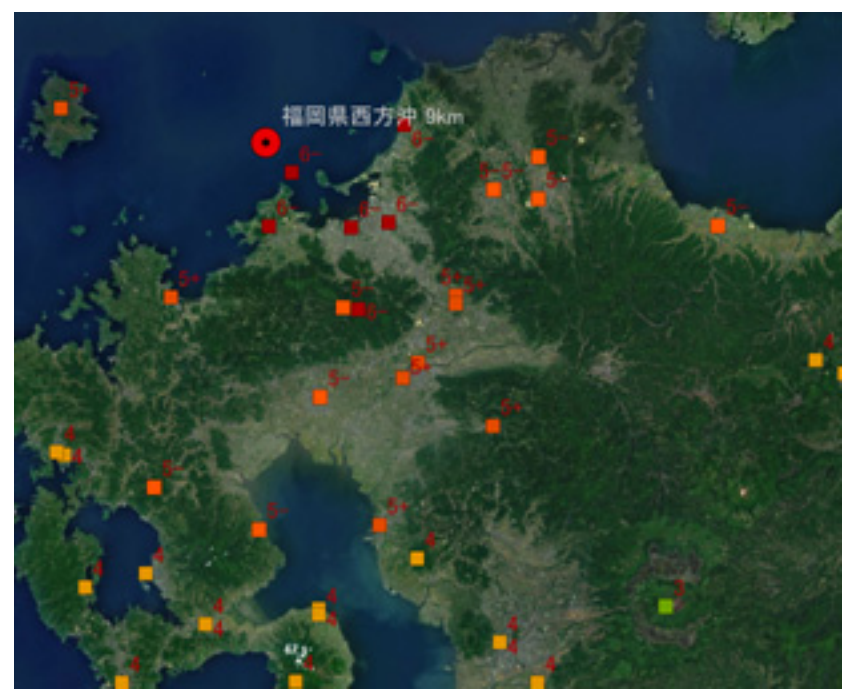

Figure 6. Earthquake scene on GIS system

First of all, the software to convert this AMeDAS data format into new JMA DPI XML data by using Java and C language was developed. Figure 7 shows the AMeDAS data format and the flow of new JMA DPI XML data conversion process. The AMeDAS data is converted to XML format according to the new DPI XML format. Figure 8 shows the result when AMeDAS data is converted into a new DPI XML format. In particular, the coordinate systems of AMeDAS data are quite important in converting in order to match with DPI XML data.

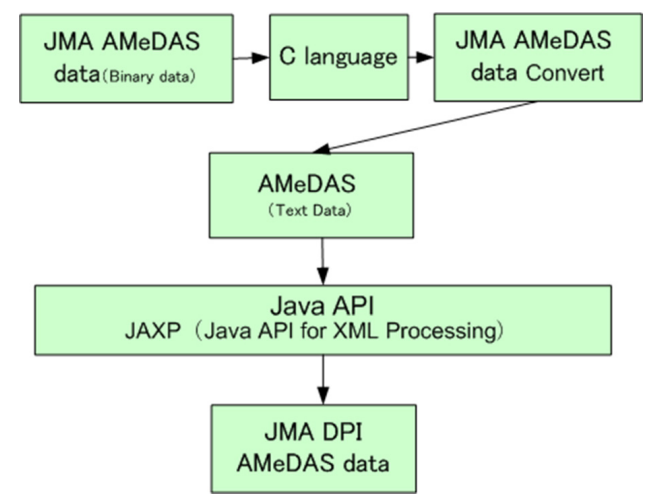

Figure 7. Flow of AMeDAS data format conversion processing

We next developed a system that could display integrated AMeDAS data and DPI XML data on a Web-based system. The system configuration in which Web-based hazard information can be monitored is shown in Figure 9. This system can monitor hazard information on Google Maps using Ajax. Figure 10 shows the flow of data processing to display hazard information in the Web-browser. This system is cheap and efficient, even though hazard information is monitored at high speed. A lot of Open Source Software was used in this system. AMeDAS XML format data is integrated with DPI XML data, and the compound data is converted to a shapefile format for GIS analysis. Figure 11 shows a scene of typhoon information and precipitation from this compound data. Also, Figure 12 shows an enlargement of Figure 11 in the heavy rain area, in which 
precipitation is clearly shown by contour lines. Figure 13 shows information 48 hours after Figure 11 in the heavy rain district.

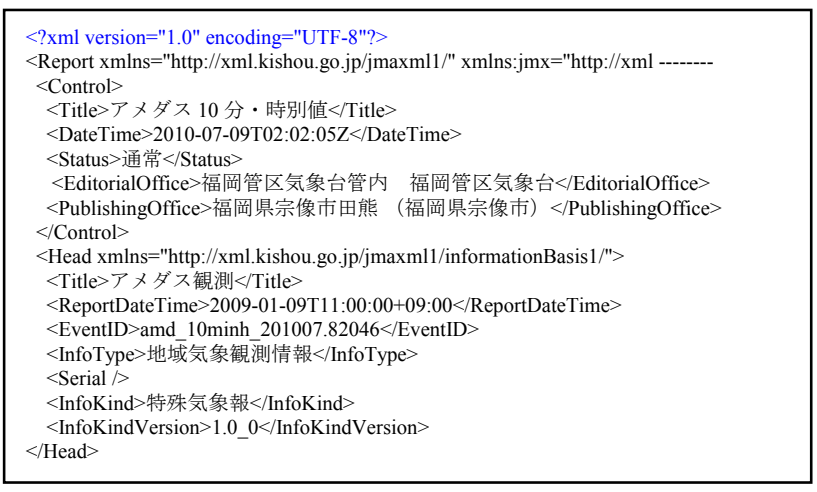

Figure 8. New AMeDAS data DPI XML

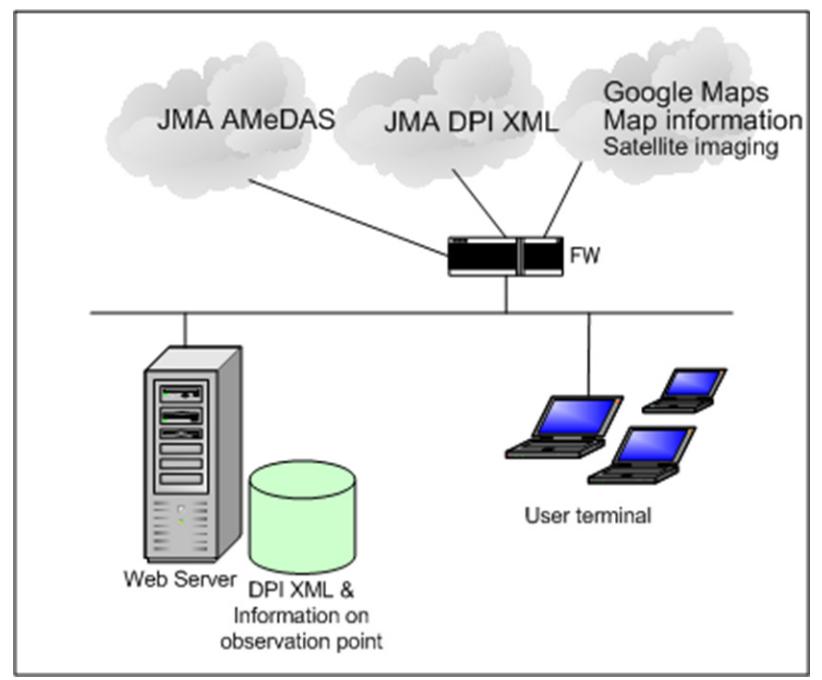

Figure 9. DPI XML integration system composition

\section{CONCLUSIONS}

We expect there will be several types of users of this system, including local governments and commercial developers. The model of the first Web-based system can monitor hazard information on $\mathrm{s}$ and typhoons, etc. by simply using the DPI XML format data. After receiving DPI XML data on several disasters via the internet from the JMA or Japan Meteorological Business Support Center (JMBSC), users can quickly monitor various scenes in browsers. It is not difficult for them to monitor by PC through implementing the JavaScript component kit received from our laboratory. The second type of user is those are able to use GIS software in their offices. They can monitor various scenes in shapefile converted from DPI XML data on a GIS framework. The conversion tool from DPI XML data to shapefile is also available from our laboratory website. Using shapefile enables a much greater variety of uses of DPI XML data. For example, the high resolution ortho images integrated with rainfall data by DPI XML data on a GIS framework are quite useful for estimating flood damage in regions. When rainfall exceeds $80 \mathrm{~mm}$ in one hour, the likelihood of a disaster increases dramatically, and a strict alert is needed. Accumulating information such as "Has it begun to rain, how long for, and to what extent?" is very important for taking action towards rainfall disaster (river flood and sediment disaster, etc.). There is no system that can handle this by integrating information on the accumulated precipitation of the JMA DPI XML data and the AMeDAS data (48-hour or 24hour etc.). Moreover, we can locally analyze the region from the content of this system as developed and shown by Ushiyama et al. (JNDS. 2003) in high resolution. This system can accumulate past disaster prevention information and regional weather information (AMeDAS). This system measures disasters and is promising though schedules are based on past events. In the flood and the sediment disasters, the hourly rainfall in the past disasters is a criterion (How much rainfall will cause the river to flood?). The GIS system that we developed is expected to be used for shelter preparation at disaster sites, giving evacuation orders, and the judgment for evacuation directives. Additional data such as Digital Elevation Models (DEM), Digital Surface Model (DSM), 1:2500 digital topographic maps from the Geographical Survey Institute (GSI), and ward area maps of local governments could be integrated with DPI XML data. In the future, varied advice from local governments or other users will be necessary to improve the present system. In particular, local hazard maps are quite important because they include various inundation zones from past floods.

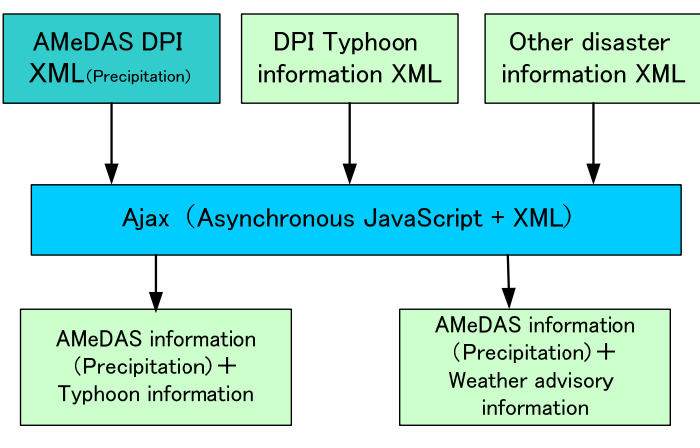

Figure 10. Flow of processing of DPI XML data

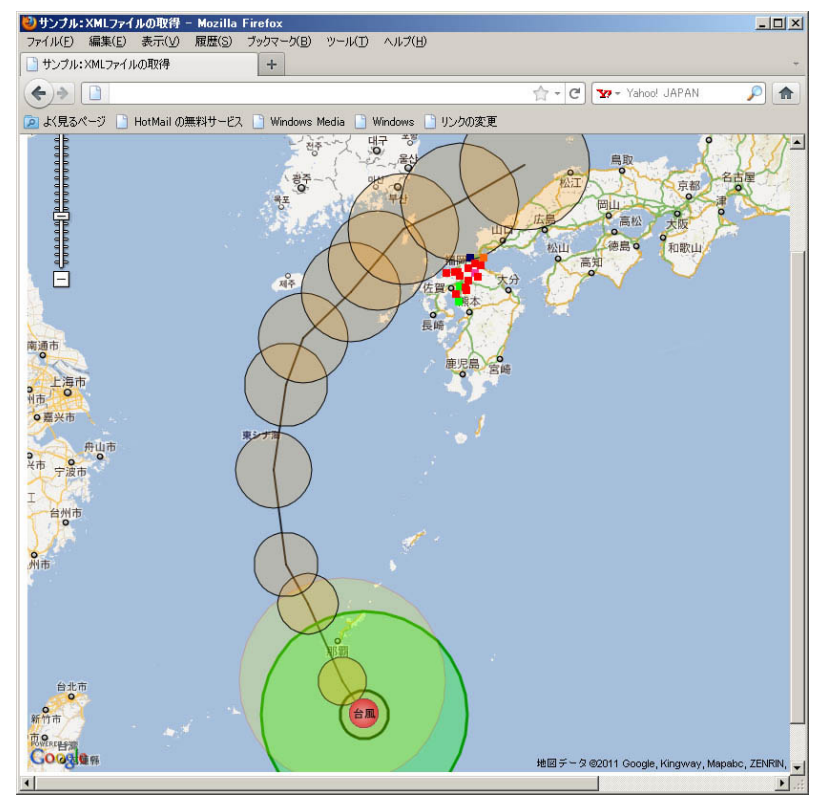

Figure 11. Typhoon scene and AMeDAS data on Google Maps 


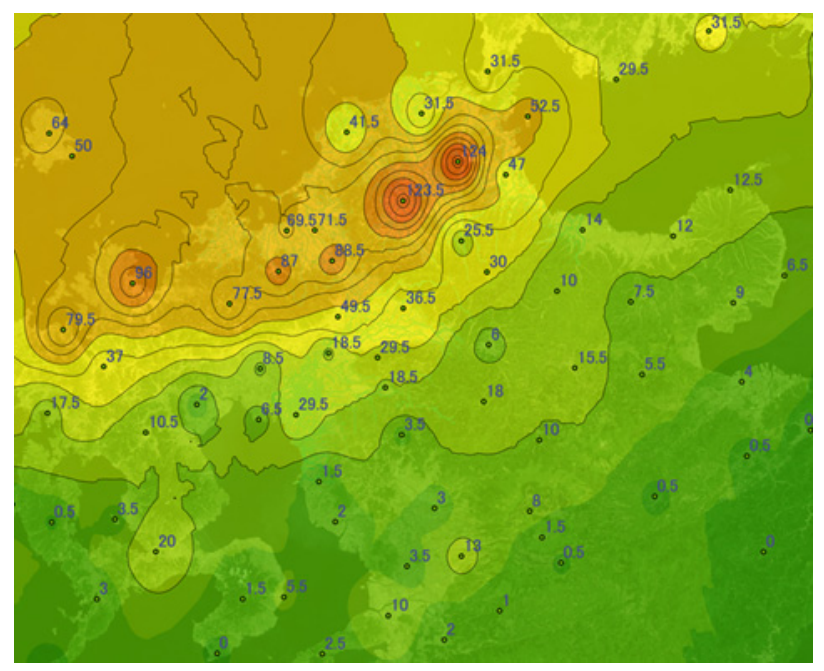

Figure 12. Enlargement of Figure 11 in the heavy rain area

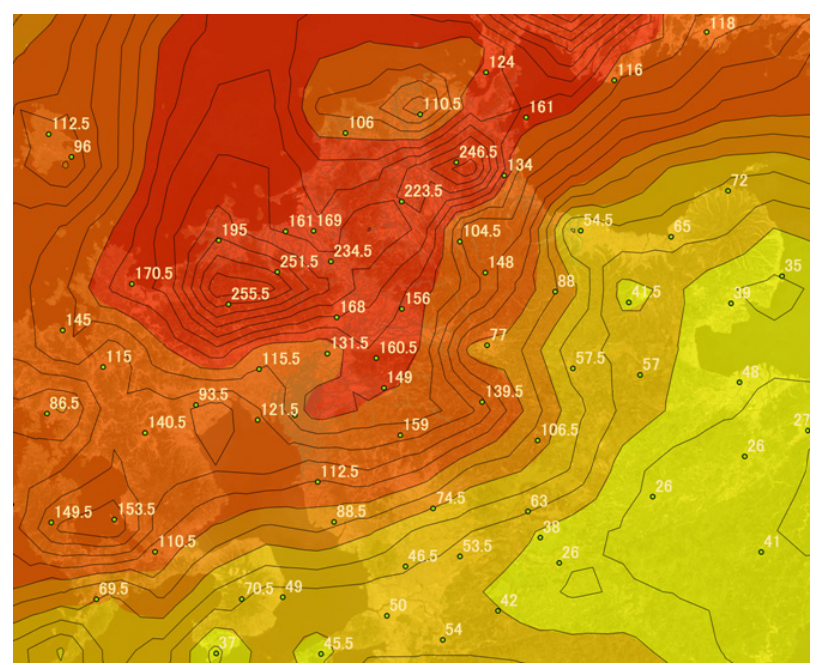

Figure 13. Expansion of Figure 11 in heavy rain district (In 48 hours)

\section{References from Journals}

Beyene, E.G., Meissner, B., 2010. Spatio-temporal analyses of correlation between NOAA satellite RFE and weather stations' rainfall record in Ethiopia. International Journal of Applied Earth Observation and Geoinformation, 12, pp. S69-S75.

Chang, C.W., Lin, P.S., Tsai, C.L., 2011. Estimation of sediment volume of debris flow caused by extreme rainfall in Taiwan. Engineering Geology, 123(1-2), pp. 83-90.

Dahal, R.D., Hasegawa, S., 2008. Representative rainfall thresholds for landslides in the Nepal Himalaya. Geomorphology, 100(3-4), pp. 429-443.

Domenikiotis, C., Dalezios, N.R., Faraslis, I., 2010. GIS-based weather radar siting procedure in mountainous terrain. Physics and Chemistry of the Earth, 35(1-2), pp. 35-42.
Iwasaki, H., Sunaga, Y., 2009. Study of Recent Variation in Weak Rainfall over Japan Using 31-Year AMeDAS Dataset. SOLA, 5, pp. 157-159.

Kanada, S., Nakano, M., Hayashi, S., Kato, T., Nakamura, M., Kurihara, K., Kitoh, A., 2008. Reproducibility of Maximum Daily Precipitation Amount over Japan by a High-resolution Non-hydrostatic Model. SOLA, 4, pp. 105-108.

Suk, Mi-Kyung., 2009. Application and analysis of the radar precipitation estimates over the South korea, 34th Conference on Radar Meteorology, P14.2-4 CD-ROM.

Ushiyama, M., Kaoru, T., 2002. An Internet-based Real-time Heavy Rainfall Display System. Journal of Natural Disaster Science, 24(2), pp. 43-49.

Ushiyama, M., 2003. Heavy Rainfall Disaster in Eastern Japan Caused by Typhoon 0206 from July 9 to 12, 2002. Journal of natural disaster science, 25(2), pp. 57-63.

\section{References from websites:}

JMA, 2011. The Japan Meteorological Agency disaster prevention information XML format dissemination, JAPAN. http://xml.kishou.go.jp (June, 2011).

JMA, 2011. The Japan Meteorological Agency Automated Meteorological Data Acquisition System information, JAPAN. http://www.jma.go.jp/jma/kishou/know/amedas/ame_master.pdf (July. 2011).

JMBSC, 2006. Japan Meteorological Business Support Center Online climatological information "Online Data Service", JAPAN. http://www.jmbsc.or.jp/hp/online/n-online0.html (July. 2011). 